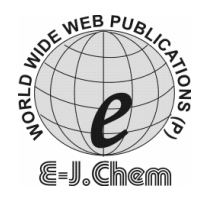

http://www.e-journals.net
ISSN: 0973-4945; CODEN ECJHAO

E-Journal of Chemistry

2009, 6(3), 737-742

\title{
Uptake of Cationic Dyes from Aqueous Solution by Biosorption onto Granular Muntingia calabura
}

\author{
T. SANTHI S. MANONMANI ${ }^{\#}$ and S. RAVI* \\ Department of Chemistry, Karpagam University, \\ Coimbatore-641021, Tamilnadu, India. \\ \#Department of Chemistry, PSG College of Arts and Science, \\ Coimbatore-641014, Tamilnadu, India. \\ ravisubban@rediffmail.com
}

Received 9 November 2008; Revised 2 June 2008; Accepted 20 January 2009

\begin{abstract}
A new, low cost, locally available biomaterial was tested for its ability to remove cationic dyes from aqueous solution. A granule prepared from a mixture of leafs, fruits and twigs of Muntingia calabura had been utilized as a sorbent for uptake of three cationic dyes, methylene blue (MB), methylene red (MR) and malachite green (MG). The effects of various experimental parameters (e.g., contact time, dye concentration, adsorbent dose and $\mathrm{pH}$ ) were investigated and optimal experimental conditions were ascertained. Above the value of initial $\mathrm{pH} 6$, three dyes studied could be removed effectively. The isothermal data fitted the Langmuir and Freundlich isotherm models for all three dyes sorption. The biosorption processes followed the pseudo-first order rate kinetics. The results in this study indicated that Muntingia calabura was an attractive candidate for removing cationic dyes from the dye wastewater.
\end{abstract}

Keywords: Muntingia calabura, Biosorption, Methylene blue, Methylene red, Malachite green.

\section{Introduction}

Contamination of the environment from a variety of sources has become an increasingly serious problem in recent years. The release of dyes into wastewater by various industries poses serious environmental problems due the persistent and recalcitrant nature of the dyes. The presence of dyes in waterways is easily detectable even in small concentrations. The coloration of the water by the dyes may have an inhibitory effect on photosynthesis affecting aquatic ecosystems. Dyes may also be problematic if they are broken down an aerobically in the sediment, as toxic amines are often produced due to incomplete degradation by bacteria. Some of the dyes or their metabolites are either toxic or mutagenic and carcinogenic ${ }^{1}$. 
Synthetic dyes have complex aromatic structures, which provide them physiochemical, thermal, biological, and optical stability. The USEPA (Environmental Protection Agency) has classified textile wastes into four groups, dispersible, hard-to-treat, high volume, hazardous and toxic wastes ${ }^{2}$. Basic dyes are the brightest class of soluble dyes used by the textile industry. The dye causes irritation to the gastrointestinal tract with symptoms of nausea, vomiting, and diarrhea. It may also cause methemoglobinemia, convulsions, and dyspnea, if inhaled. It is likely to cause irritation to the skin ${ }^{3}$. Hence, it is necessary to remove dyes from wastewater.

Many methods are available for the removal of dyes from waters. Among these methods, adsorption is by far the most versatile and widely used method because of its low cost, ease of operation. A number of agricultural waste and by-products of cellulosic origin have been studied for their capacity to remove dyes from aqueous solutions, such as peanut hulls ${ }^{4}$, maize bran ${ }^{5}$, sawdust ${ }^{6}$, sugar beet pulp ${ }^{7}$, crab shell $^{8}$, cornstarch $^{9}$, rice husk ${ }^{10}$, chitin $^{11}$, orange waste $^{12}$, lemon peel ${ }^{13}$, granular kohlrabi peel ${ }^{14}$, raw barley straw and sago waste ${ }^{15}$.

Therefore, there is the need to look for low cost alternatives in easily available biomaterials, which can adsorb dyes from wastewaters. In the present work, we attempt to use an agricultural by-product, the mixtures of leafs, fruits and twigs of Muntangia calibura, as adsorbent for the removal of dyes from water. These sorbents can be used once, and then disposed as fuel for power generation or as a fermentation substrate to produce fertilizer for vegetable cultivation.

\section{Experimental}

\section{Preparation of the muntangia calibura sorbent}

The M. calibura was obtained from an agricultural farm in Coimbatore District (Tamilnadu). The mixtures of leafs, fruits and twigs of M. calibura was washed thoroughly with distilled water, air- dried and powdered in a grinder, and then preserved in a desiccator for use.

\section{Preparation of cationic dye solutions}

Methylene blue in commercial purity obtained from Fluka was used without further purification. The dye stock solutions were prepared by dissolving accurately weighted dyes in distilled water to the concentration of $500 \mathrm{mg} / \mathrm{L}$. The experimental solutions were obtained by diluting the dye stock solutions in accurate proportions to different initial concentrations.

\section{Experimental methods and measurements}

Bioadsorption experiments were carried out in a rotary shaker at $150 \mathrm{rpm}$ using $250 \mathrm{~mL}$ shaking flasks containing $50 \mathrm{~mL}$ of dye solutions at different concentrations and initial $\mathrm{pH}$ values. The initial $\mathrm{pH}$ values of the solutions were previously adjusted with $0.1 \mathrm{M} \mathrm{HCl}$ or $\mathrm{NaOH}$ using a DEEP VERSION model (EI) $\mathrm{pH}$ meter. The adsorbent $(0.2 \mathrm{~g})$ was added to each flask, and then the flasks were sealed to prevent any change in volume during the experiments. After shaking the flasks for a predetermined time interval, the samples were withdrawn from the flasks and the dye solutions were separated from the adsorbent by filtration after centrifugation. The $\mathrm{pH}$ values of the separated dye solutions were again measured for estimating their change. Dye concentrations in the supernatant solutions were estimated by measuring absorbance at maximum wavelengths of dye with a Systronic Spectrophotometer104. The amount of dye adsorbed by the biomass was calculated using the following equation:

$$
\mathrm{q}=\left(\mathrm{C}_{0}-\mathrm{C}_{\mathrm{e}}\right) \mathrm{V} / \mathrm{W}
$$


where, $\mathrm{q}(\mathrm{mg} / \mathrm{g})$ is the amount of dye adsorbed by the biomass, $\mathrm{C}_{0}$ and $\mathrm{Ce}(\mathrm{mg} / \mathrm{L})$ are the initial and equilibrium liquid-phase concentration of dye. $\mathrm{V}(\mathrm{L})$ is the initial volume of dye solution and $\mathrm{W}(\mathrm{g})$ is the weight of the biomass.

The effect of each parameter was studied by fixing the values of other parameters. The experiments were conducted with duplicate and the negative controls (with no adsorbent) to ensure that adsorption was by the mixtures of leafs, fruits and twigs of $M$. calibura biomass and not by the container.

\section{Results and Discussion}

\section{Influence of initial $\mathrm{pH}$}

The effect of initial $\mathrm{pH}$ on biosorption percentage of dyes was examined over a range of $\mathrm{pH}$ values from 2 to 10 and the results are presented in Figure 1. For all three dyes, the dye removal was minimum at the initial $\mathrm{pH}$ 2. The dyes sorbed increased as the $\mathrm{pH}$ was increased from $\mathrm{pH} 2$ to 6 , then, the dye removal was decreased beyond $\mathrm{pH} 6$. For this reason, $\mathrm{pH} 6$ was selected for future experiments.

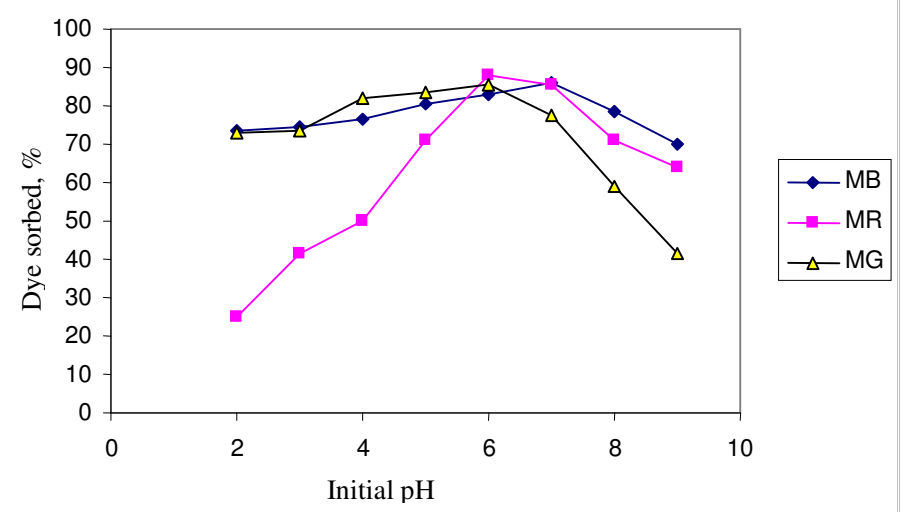

Figure 1. Influence of initial $\mathrm{pH}$ on biosorption of MB, MR and MG by the mixtures of leafs, fruits and twigs of Muntangia calibura (sorbent dose: $200 \mathrm{mg} / 50 \mathrm{~mL}$; contact time: $3 \mathrm{~h}$; dye concentration: $100 \mathrm{mg} / \mathrm{L}$ ).

After adsorption experiments, it was found that at low $\mathrm{pH}$ and at high $\mathrm{pH}$, the dye become protonated, the electrostatic repulsion between the protonated dyes and positively charged adsorbent sites results in decreased adsorption. Higher adsorption at $\mathrm{pH} 6$ may be due to increased protonation by the neutralization of the negative charges at the surface of the adsorbent; which facilitates the diffusion process and provides more active sites for the adsorbent.

\section{Influence of initial dye concentration}

The influence of dye concentration on bioadsorption of dyes is shown in Figure 2. When the dye concentration was increased from 25 to $200 \mathrm{mg} / \mathrm{L}$, the percentage of dye adsorbed was between $38.2 \%$ and $93.64 \%$.

With the data in Figure 2, the Langmuir and Freundlich equation were employed to study the adsorption isotherms of dyes.

The linearised form of the Langmuir equation is as follows

$$
\mathrm{C}_{\mathrm{e}} / \mathrm{q}_{\mathrm{e}}=1 /\left(\mathrm{a} \mathrm{Q}_{\mathrm{m}}\right)+\mathrm{C}_{\mathrm{e}} / \mathrm{Q}_{\mathrm{m}}
$$




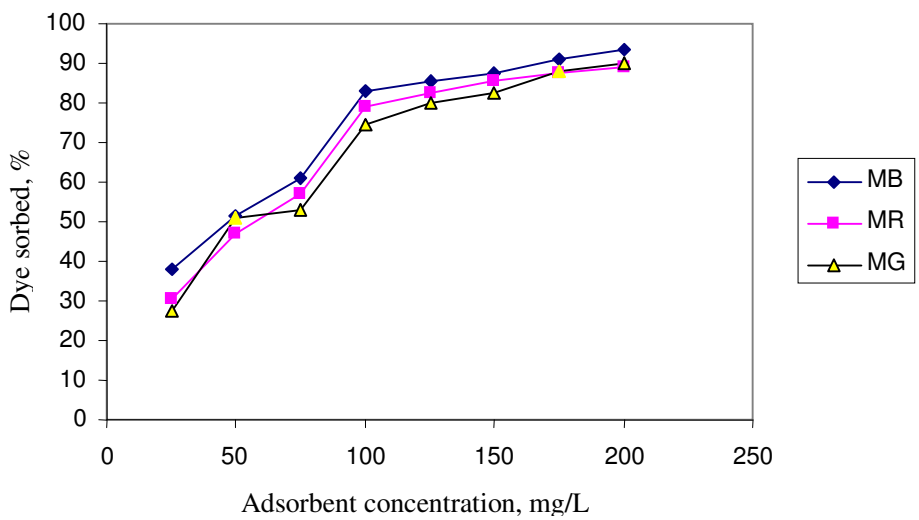

Figure 2. Influence of dye concentration on biosorption of $M B, M R$, and $M G$ by the mixtures of leafs, fruits and twigs of Muntangia calibura (sorbent dose: $200 \mathrm{mg} / 50 \mathrm{~mL}$; contact time: $3 \mathrm{~h} ; \mathrm{pH}: 6.0$ ).

where, $C_{e}(\mathrm{mg} / \mathrm{L})$ is the concentration of the dye solution at equilibrium, $\mathrm{q}_{\mathrm{e}}(\mathrm{mg} / \mathrm{g})$ is the amount of dye sorbed at equilibrium, $\mathrm{Q}_{\mathrm{m}}$ is the maximum adsorption capacity and represents a practical limiting adsorption capacity when the adsorbent surface is fully covered with monolayer adsorbent molecule and a is Langmuir constant. The $\mathrm{Q}_{\mathrm{m}}$ and a values are calculated from the slopes $\left(1 / \mathrm{Q}_{\mathrm{m}}\right)$ and intercepts $\left(1 / \mathrm{a} \mathrm{Q}_{\mathrm{m}}\right)$ of linear plots of $\mathrm{C}_{\mathrm{e}} / \mathrm{q}_{\mathrm{e}}$ versus $\mathrm{C}_{\mathrm{e}}$.

The linearised form of the Freundlich equation is as follows:

$$
\ln \mathrm{Q}_{\mathrm{e}}=\ln \mathrm{K}+(1 / \mathrm{n}) \ln \mathrm{C}_{\mathrm{e}}
$$

Where $\mathrm{Q}_{\mathrm{e}}$ is the amount of dye adsorbed at equilibrium, Ce is the concentration of the dye solution at equilibrium and $1 / \mathrm{n}$ are empirical constant and indicate adsorption capacity and intensity, respectively. Their values were obtained from the intercepts (ln K) and slope $(1 / n)$ of linear plots of $\ln \mathrm{Q}_{\mathrm{e}}$ versus $\ln \mathrm{C}_{\mathrm{e}}$.

The $\mathrm{Q}_{\mathrm{m}}$ and a values in the Langmuir equation, the $\mathrm{k}$ and $1 / \mathrm{n}$ values in the Freundlich equation are given in the Table 1. From the results in Table 1, it could be concluded that the sorption of all three dyes followed the Langmuir and Freundlich model of adsorption.

Table 1. The $Q_{m} \&$ a values in the Langmuir equation, the $K$ and $1 / n$ values in Freundlich equation.

\begin{tabular}{ccccc}
\hline & Langmuir & \multicolumn{3}{c}{ Freundlich } \\
Dye & $\mathrm{Q}_{\mathrm{m}} \mathrm{mg} / \mathrm{g}$ & $\mathrm{a}$ & $\mathrm{k}$ & $1 / \mathrm{n}$ \\
\hline MB & 20.00 & 0.0510 & 5.6234 & 1.0000 \\
MR & 58.21 & 0.1857 & 6.7608 & 0.6666 \\
MG & 32.50 & 0.03496 & 7.7620 & 0.5000 \\
\hline
\end{tabular}

\section{Effect of adsorbent dose}

The adsorption of the dyes was studied by varying the concentration of the mixtures of the leafs, fruits and twigs of $M$. calibura $(0.1-2 \mathrm{~g} / \mathrm{mL})$. The percentage of adsorption increased as the adsorbent concentration increased from $0.1 \mathrm{~g}$ to $0.4 \mathrm{~g}$ and attain equilibrium beyond $0.4 \mathrm{~g} / \mathrm{mL}$ shown in Table 2 . The increase in the percent removal of dyes with the increase in adsorbent dosage is due to the availability of larger surface area with more active functional groups at higher adsorbent dosages and saturation occurs as a result of non-availability of active sites on the adsorbent. 
Table 2. Effect of adsorbent dosage on biosorption of dyes (dye concentration: $100 \mathrm{mg} / \mathrm{L}$; contact time: $3 \mathrm{~h} ; \mathrm{pH}: 6.0$ ).

\begin{tabular}{cccc}
\hline Adsorbent & \multicolumn{3}{c}{ Dye adsorbed, \% } \\
\cline { 2 - 4 } concentration, mg/L & MB & MR & MG \\
\hline 100 & 72.85 & 69.38 & 70.00 \\
200 & 83.18 & 79.10 & 74.74 \\
300 & 86.96 & 85.29 & 82.11 \\
400 & 93.95 & 89.10 & 84.89 \\
600 & 93.16 & 88.30 & 85.02 \\
800 & 94.00 & 89.40 & 84.31 \\
1000 & 93.00 & 90.32 & 84.92 \\
1200 & 93.64 & 89.23 & 84.81 \\
\hline
\end{tabular}

\section{Adsorption kinetics}

The kinetic data were treated with the following Lagergren's pseudo-first order rate equation:

$$
\log \left(\mathrm{q}_{\mathrm{e}}-\mathrm{q}_{\mathrm{t}}\right)=\log \mathrm{q}_{\mathrm{e}}-\mathrm{k}_{\mathrm{ad}} \mathrm{t} / 2.303
$$

where, $\mathrm{q}_{\mathrm{e}}$ and $\mathrm{q}_{\mathrm{t}}(\mathrm{mg} / \mathrm{g})$ referring to the amount of dye adsorbed at equilibrium and time $t$ (min), respectively, and $\mathrm{k}_{\mathrm{ad}}$ is the rate constant. The rate constant $\mathrm{k}_{\mathrm{ad}}$ could be calculated from the slopes of the linear plots of $\log \left(\mathrm{q}_{\mathrm{e}}-\mathrm{q}_{\mathrm{t}}\right)$ verses $t$. The Lagergren plots of dye biosorption are shown in Figure 3. The high values of correlation coefficients showed that the data conformed well to the pseudo-first order rate kinetic model.

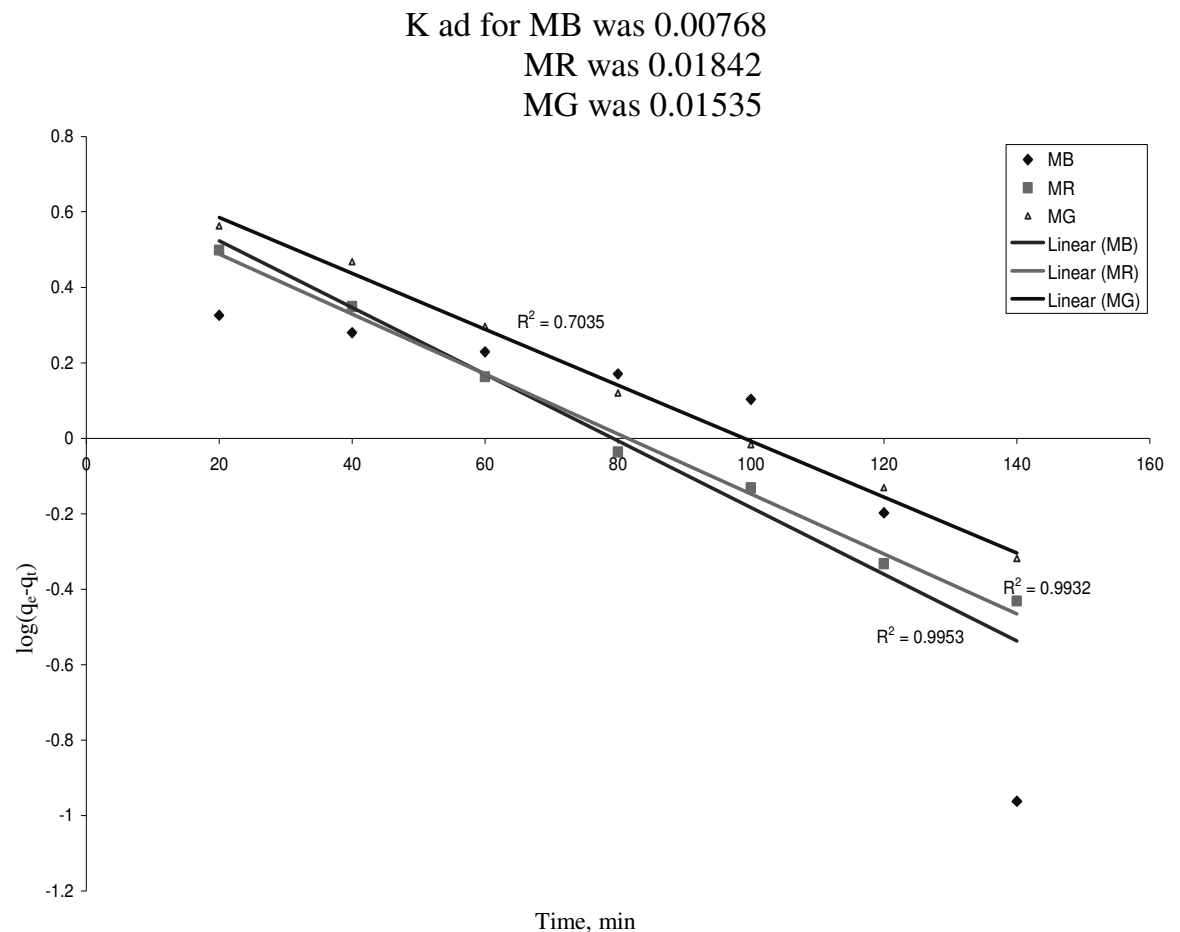

Figure 3. Lagergren plots for biosorption of MB, MR, and MG by the mixtures of leafs, fruits and twigs of Muntangia calibura ( sorbent dose: $200 \mathrm{mg} / 50 \mathrm{~mL}$; contact time: $3 \mathrm{~h}$; $\mathrm{pH}$ : 6.0). 


\section{Spectrochemical characterization}

The FT-IR spectrum of the mixtures of leafs, fruits and twigs of M. calibura showed that the most prominent peaks in the spectrum originate from $\mathrm{OH}$ vibrations $\left(3404-3284 \mathrm{~cm}^{-1}\right.$ ), $\mathrm{CH}_{2}$ and $\mathrm{CH}_{3}$ asymmetric and symmetric stretching vibrations (2990-2850 $\left.\mathrm{Cm}^{-1}\right)$. Peaks in region (1664-1251 $\mathrm{cm}^{-1}$ ) originate from the stretching mode of carbonyls mainly ketons and esters. The peaks at $\left(1155-1033 \mathrm{~cm}^{-1}\right)$ region related to lignin. Therefore, it is possible that cellulose, hemicelluloses as well as lignin, having many $\mathrm{OH}$ groups in their structure, make the most absorbing layer. The absence of hydroxyl and carbonyl group peaks in the IR spectra recorded after the absorption of the dyes indicates that hydroxyl and carbonyl groups are involved in the dye absorption.

\section{Conclusions}

This study confirmed that the biosorbent prepared from the leafs, fruits and twigs of $M$. calibura, a low cost agricultural waste, could effectively remove MB , MR and MG from an aqueous solution. The optimal $\mathrm{pH}$ for favorable sorption of dyes was 6 . The sorption equilibrium was reached in approximately $3 \mathrm{~h}$. The isothermal data fitted the Langmuir and Freundlich model for all three dyes sorption. The biosorption processes followed the pseudo-first order rate kinetics.

\section{References}

1. Sivaraj R, Namasivayam C and Kadirvelu K, Waste Management, 2001, 21, 105.

2. Arami M, Yousefi Limaee N, Mahmoodi N M and Tabrizi N S, J Colloid Interface Sci., 2005, 288, 371.

3. Senthilkumaar S, Varadarajan P R, Porkodi K and Subbhuraam C V, J Colloid Interface Sci., 2005, 284, 78.

4. Brown P, Jefcoat I A, Parrish D, Gill S and Graham E, Adv Environ Res., 2000, 4, 19.

5. Singh K K, Talat M and Hasan S H, Biores Technol., 2006, 97, 2124.

6. Taty-Costodes V C, Fauduet H, Porte C and Delacroix A, J Hazard Mater., 2003, $\mathbf{1 0 5}, 121$.

7. Reddad Z, Gerente C, Andres Y and Cloirec P L, Environ Sci Technol., 2002, 36, 2067.

8. Vijayaraghavan K, Palanivelu K and Velan M, Biores Technol., 2006, 97, 1411.

9. Kweon D K, Choi J K, Kim E K and Lim S T, Carbohydr Polym., 2001, 46, 171.

10. Kumar U and Bandyopadhyay M, Biores Technol., 2006, 97, 104.

11. Ghimire K N, Inoue K, Miyajima T, Yoshizuka K and Shoji T, Chitin Res., 2001, 7(2), 61.

12. Dhakal R P, Ghimire K N, Inoue K, Yano M and Makino K, Sep Pur Technol., 2005, 42, 219.

13. Vasanth Kumar K, Dyes and Pigments, 2007, 74, 595.

14. Renmin Gong, Xiaoping Zhang, Huijun Liu, Yingzhi Sun and Birong Liu, Biores Technol., 2007, 98, 1319.

15. Husseien M, Amer A A, Azza EI- Maghraby, Nahla A and Taha, J Appl Sci Res., 2007, 3(11), 1352. 


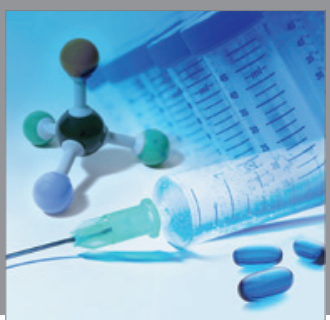

International Journal of

Medicinal Chemistry

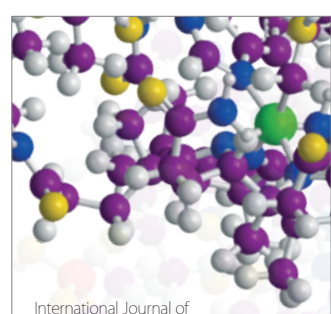

Carbohydrate Chemistry

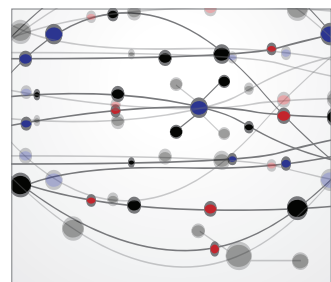

The Scientific World Journal
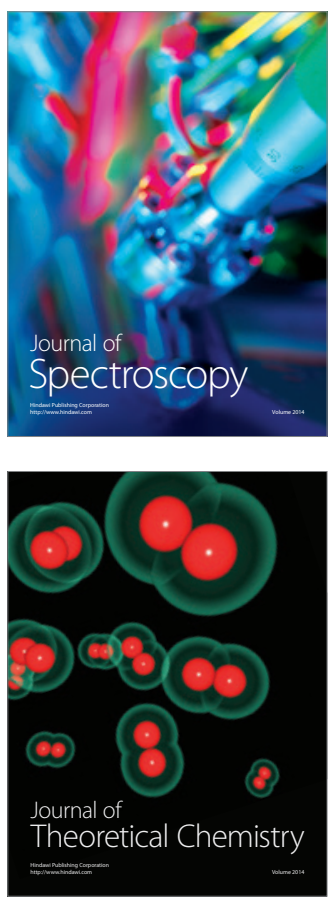
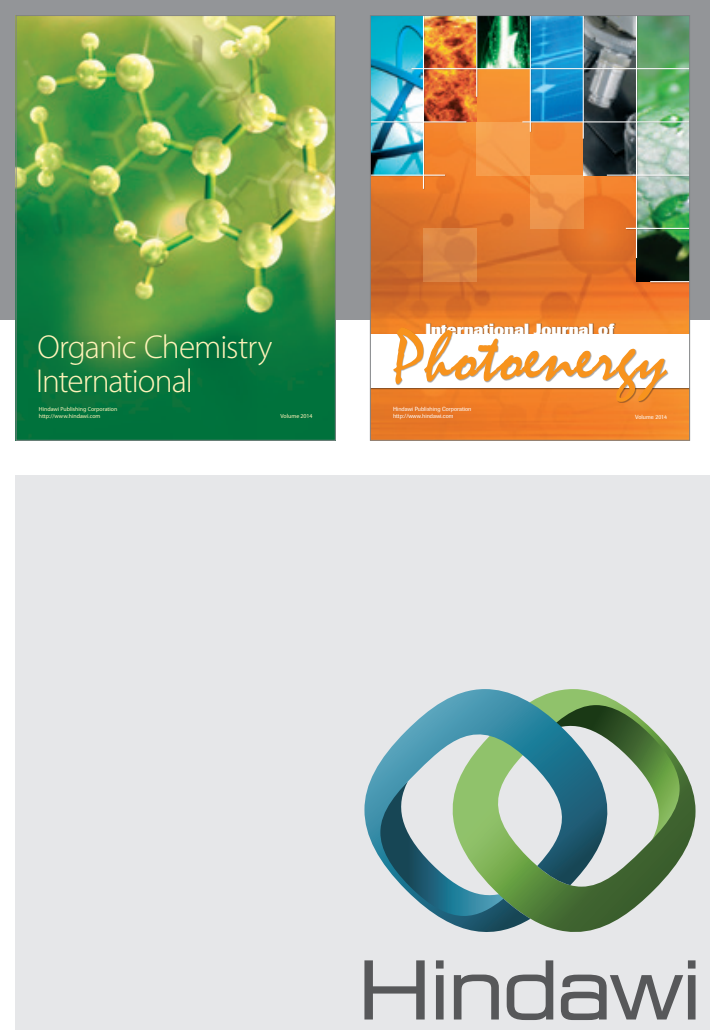

Submit your manuscripts at

http://www.hindawi.com
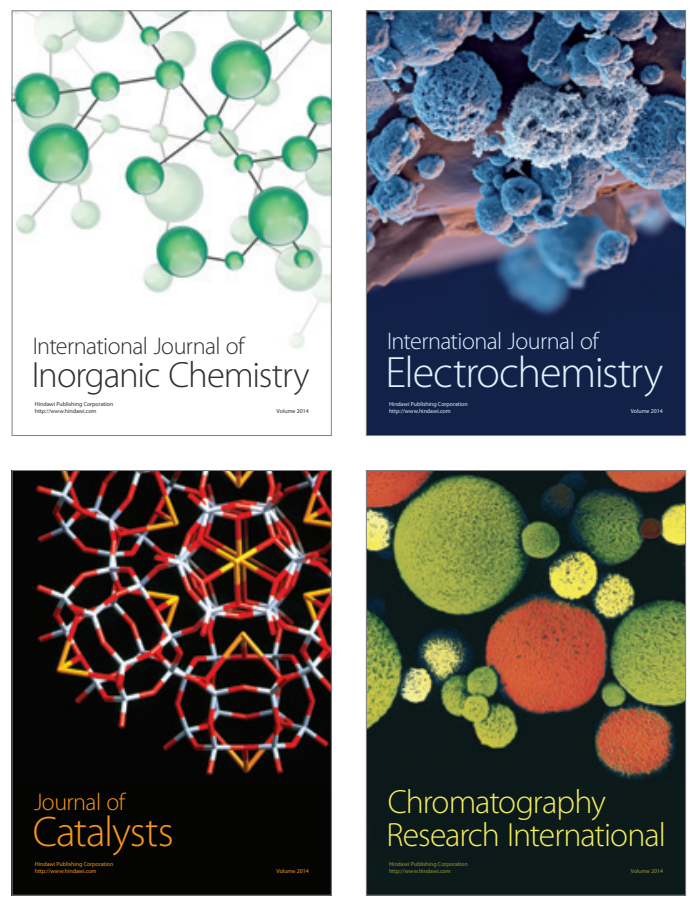
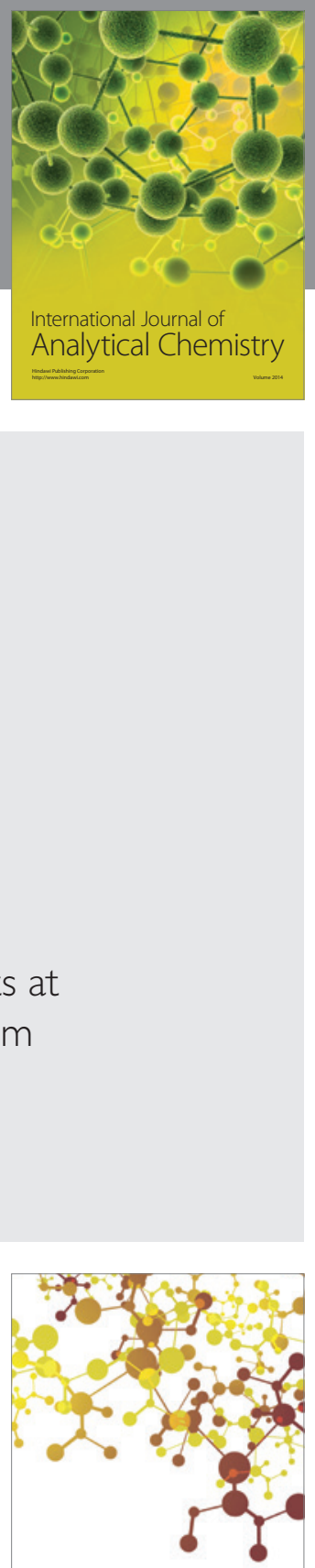

Journal of

Applied Chemistry
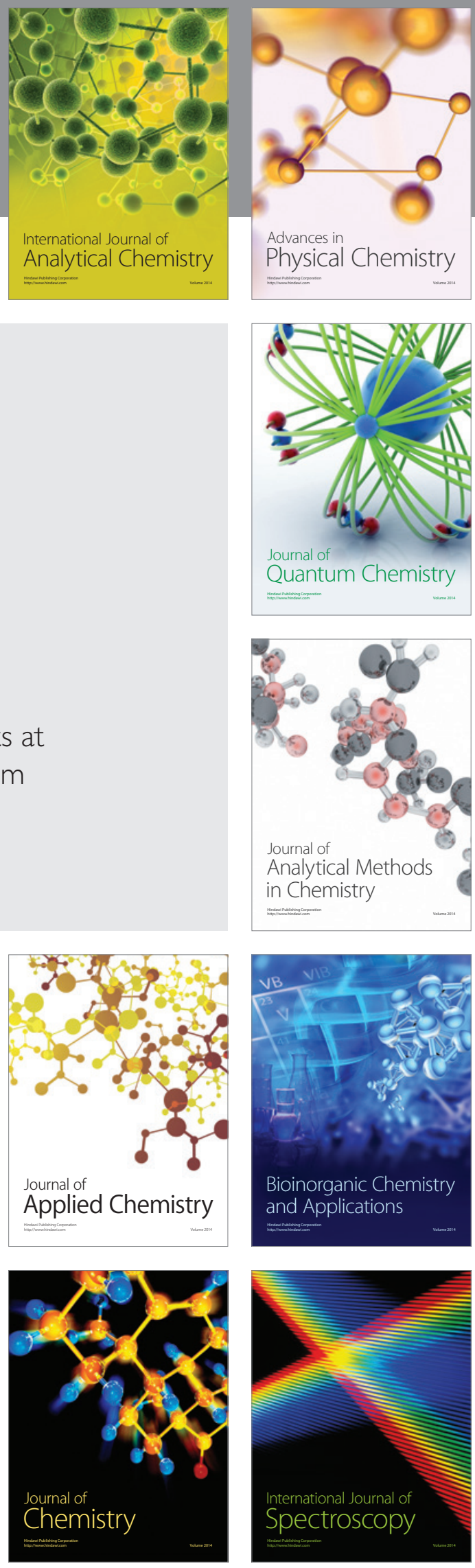